\title{
AGRICULTURA ORGÂNICA E AGROECOLOGIA COMO FERRAMENTA DE EDUCAÇÃO AMBIENTAL E ALIMENTAR
}

\author{
Lucas Lenin Resende de ASSIS ${ }^{1}$ \\ Iberê Martí Moreira da SILVA ${ }^{2}$ \\ Luís Claudio Paterno SILVEIRA ${ }^{3}$
}

\begin{abstract}
Resumo
Por meio de uma abordagem participativa sistêmica, a agroecologia tende a desempenhar papéis educacionais e pedagógicos fundamentais entre todas as partes interessadas e, particularmente, os mais jovens (por exemplo, crianças de escolas primárias). Nessa perspectiva, o presente trabalho utilizou uma investigação qualitativa baseada em questionários, dirigida a crianças de nove a 10 anos de uma escola pública do município de Lavras - MG (Brasil). O objetivo final foi avaliar o potencial da Agroecologia e Agricultura Orgânica (AOA) como ferramenta pedagógica para o ensino da educação alimentar e a sensibilização ambiental deste público jovem. Além de mostrar que tal desconhecimento estava intrinsecamente ligado a fatores socioeconômicos, os resultados revelaram que os escolares frequentemente se dissociam da universidade e seus papéis como prestadora de serviços educacionais à sociedade. Há, portanto, uma necessidade urgente de desenvolver abordagens mais multidisciplinares e inovadoras para o ensino da agroecologia atingir um público mais amplo.
\end{abstract}

Palavras-chave: Ensino. Agricultura urbana. Saúde alimentar. Horta. Agricultura alternativa.

\footnotetext{
${ }^{1}$ Engenheiro Agrônomo, Mestre em Fitotecnia, doutorando em Ciência do Solos pela Universidade Federal de Lavras (UFLA), Lavras - MG, Brasil. ORCID: https://orcid.org/0000-0002-8767-2189

E-mail: ll.resende@outlook.com

${ }^{2}$ Engenheiro Florestal, Mestre em Engenharia Florestal e Doutor em Agronomia/Plantas Medicinais pela Universidade Federal de Lavras (UFLA), Lavras - MG, Brasil. Engenheiro Florestal pela Unemat. ORCID: https://orcid.org/00000002-5229-3752

E-mail: iberemarti@gmail.com

${ }^{3}$ Engenheiro Agrônomo, Mestre em Entomologia pela ESALQ, Doutor em Agronomia pela Universidade Federal de Lavras (UFLA), Lavras - MG, Brasil e pós-doutorado pela ESALQ em Controle Biológico Conservativo. Professor Associado IV do magistério superior do Departamento de Entomologia na Universidade Federal de Lavras (UFLA), Lavras - MG, Brasil. ORCID: https://orcid.org/0000-0003-0391-3676

E-mail: lcpsilveira@ufla.br
} 


\title{
ORGANIC AGRICULTURE AND AGROECOLOGY AS A METHOD FOR ENVIRONMENTAL AND FOOD EDUCATION
}

\author{
Lucas Lenin Resende de ASSIS \\ Iberê Martí Moreira da SILVA \\ Luís Claudio Paterno SILVEIRA
}

\begin{abstract}
Through a systemic participatory approach, agroecology tends to play key educational and pedagogical roles among all stakeholders and particularly the youngest ones (i.e., children of elementary schools). In this perspective, the present work used a qualitative questionnaire based investigation targeting 9 to 10 years old children of a public school in the municipality of Lavras MG (Brazil). The ultimate aim was to assess the potential of Agroecology and Organic Agriculture (AOA) as pedagogical tool for teaching food education and raising environmental awareness among this young public. Moreover, besides showing that such lack of knowledge was inherently linked to socio-economic factors, results revealed that school children are frequently dissociated from the university and its roles as a provider of educational services to society. There is thus an urgent need to develop more multidisciplinary and innovative approaches for agroecology teaching to reach a wider public.
\end{abstract}

Keywords: Education. Urban agriculture. Food health. Vegetable garden. Alternative agriculture. 


\title{
LA AGRICULTURA ORGÁNICA Y LA AGROECOLOGÍA COMO MÉTODO DE EDUCACIÓN AMBIENTAL Y ALIMENTARIA
}

\author{
Lucas Lenin Resende de ASSIS \\ Iberê Martí Moreira da SILVA \\ Luís Claudio Paterno SILVEIRA
}

\begin{abstract}
Resumen
Mediante un enfoque sistémico participativo, la agroecología tiende a desempeñar funciones educativas y pedagógicas fundamentales entre todos los interesados y en particular los más jóvenes (por ejemplo, los niños de la escuela primaria). Desde esta perspectiva, el presente trabajo utilizó una investigación cualitativa basada en cuestionarios, dirigida a niños de nueve a diez años de edad en una escuela pública del municipio de Lavras-MG (Brasil). El objetivo final era evaluar el potencial de la Agroecología y la Agricultura Orgánica (AOA) como herramienta pedagógica para enseñar educación alimentaria y conciencia ambiental a este joven público. Además de mostrar que esa ignorancia estaba intrínsecamente vinculada a factores socioeconómicos, los resultados revelaron que los escolares a menudo se disociaban de la universidad y de sus funciones como proveedores de servicios educativos para la sociedad. Por consiguiente, existe una necesidad urgente de elaborar enfoques más multidisciplinarios e innovadores para la enseñanza de la agroecología a fin de llegar a un público más amplio.
\end{abstract}

Palabras clave: Transmisión de conocimiento. Agricultura urbana. salud de los alimentos. Huerta. Agricultura alternativa. 


\section{Introdução}

Desde a infância as crianças têm contato com os adultos e outras pessoas que diretamente ou indiretamente as influenciam em suas ações, seja na maneira de vestir, de se comportar, de expressar e, também, de se alimentar. A alimentação desde o início da vida é muito importante para o desenvolvimento da criança, e deve ser fornecida em quantidade e qualidade adequadas, como determina a Organização Mundial da Saúde (OMS) e indica a Organização para a Alimentação e a Agricultura - FAO (ZIEGLER, 2013).

Nos dias de hoje, tem sido difícil garantir uma alimentação saudável e de procedência confiável. Existem doenças diretamente relacionadas a má alimentação como sobrepeso, desnutrição, hipertensão e que podem provocar e/ou potencializar outras como depressão, problemas cardiovasculares, diabetes e osteoporose. Essas doenças podem ser potencialmente evitadas se houver uma educação alimentar voltada para as crianças, pois podem estar relacionadas a uma alimentação deficiente em qualidade, arroladas com consumo de alimentos industrializados e sem referência local (RAMOS, 2011).

Alguns estudos relatam que, as mudanças de uma alimentação mais saudável para uma mais industrializada, estão relacionadas com o último processo de intensificação agrícola, denominado Revolução Verde. Este ocorreu de maneira global, e na agricultura brasileira iniciou-se na década de 1970, onde um pacote tecnológico de produção convencional e intensiva foi importado e disseminado, passando a fomentar técnicas como a monocultura, o uso de sementes geneticamente modificadas e uso em larga escala de adubos sintéticos e agrotóxicos (RAMOS, 2011). Infelizmente, na época de sua implantação, o debate público a respeito da qualidade dos alimentos produzidos neste novo sistema, sobretudo os efeitos nocivos dos agrotóxicos à saúde humana e ao ambiente, foram poucos e insuficientes.

Em termos mundiais, a conscientização sobre os problemas do uso de agrotóxicos na agricultura foi trazida à luz pelo trabalho intitulado Primavera Silenciosa (do inglês, Spring Silent), de Rachel Carson (1962). Este livro foi a primeira declaração pública de que o uso de químicos estava levando vários ecossistemas à morte. Desde 1944, Carson já sabia sobre os riscos do uso do inseticida Dicloro-Difenil-Tricloroetano (DDT): este produto poderia levar a morte tanto de insetos considerados pragas, como também de insetos benéficos e devido ao seu efeito ser muito intenso, também alteraria o equilíbrio ecológico. Informação que era conhecida por alguns pesquisadores, mas desconhecida pela população mundial (ALMANZA, 2009). Inclusive, atualmente, diversos estudos no Brasil vêm relatando problemas e preocupações quanto ao uso de agrotóxicos para a 
saúde humana (PIGNATI, 2017). Além dessa perspectiva, adquirir alimentos da localidade possibilita maior debate em relação à qualidade dos alimentos na promoção da saúde, ao permitir que as pessoas possam refletir a respeito de sua qualidade de vida, hábitos saudáveis, proporcionando bens, direitos e recursos aplicáveis à vida cotidiana. Sendo a escola, espaço importante e favorável para inserir o debate a respeito da educação ambiental e alimentar.

A alimentação equilibrada e balanceada é fundamental para o bom desenvolvimento físico, psíquico e social das crianças (VASCONCELOS, 2008). A preocupação com deficiências nutricionais e a fome, realidade que ainda presenciamos, tem tomado espaço na discussão do consumo excessivo de certos nutrientes e calorias na dieta, além dos problemas relativos à contaminação química dos alimentos, ou ainda, o consumo de alimentos com baixo teor nutricional e que oferecem riscos à saúde, podendo causar diabetes, obesidade e outras doenças crônicas relacionadas a alimentação. A aliança de temas como saúde, alimentação, educação e agroecologia é essencial, pois permite que as crianças exponham suas experiências particulares e exercitem um ensino dinâmico e prático, fortalecendo ainda mais o aprendizado em concordância com os princípios e conceitos agroecológicos.

Atualmente tem-se feito constante referência ao termo "Agroecologia”, que consiste em um leque de outras definições tais como: “uma agricultura socialmente justa”, “equilíbrio entre solo, plantas e animais”, “ambiente equilibrado, em que tiramos o alimento da terra sem esgotar seus insumos”, “sustentabilidade socioambiental e cultural”, dentre outras. A Agroecologia vem para somar as práticas de manejo adequado dos recursos naturais, nos fazendo entende-la como ciência que estabelece bases para a construção de estilos de agricultura sustentáveis e estratégias de desenvolvimento sustentável rural, mas que se extrapola para áreas urbanas e reflete nas nossas ações de valorização do campo, como é explicado:

Ademais, faz-se necessário considerar, também, que a prática da agricultura envolve um processo social, integrado a sistemas econômicos e que, portanto, qualquer enfoque baseado simplesmente na tecnologia ou na mudança da base técnica da agricultura pode implicar no surgimento de novas relações sociais, de novo tipo de relação dos homens com o meio ambiente e, entre outras coisas, em maior ou menor grau de autonomia e capacidade de exercer a cidadania (CAPORAL, 2004, p. 10-11).

A agroecologia, ainda que presente pontualmente na comunidade e de maneira menos expressiva do que poderia ser, tem ganhado cada vez mais espaço, se tornando uma necessidade, com vista a promover a conservação dos recursos naturais existentes e recuperação daqueles explorados de maneira desenfreada, movida pela ganância do ser humano. Em resumo, se consolida com enfoques científicos embasados em outras disciplinas e linhas de pensamento, como os saberes populares, experiências dos agricultores e de base científica que contribua na promoção das 
transformações sociais necessárias para gerar padrões de produção e consumo mais sustentáveis (CAPORAL, 2004).

Nessa perspectiva a Agroecologia é considerada uma ciência, uma prática e um movimento que assume também o debate relacionado as políticas públicas de promoção da saúde, da alimentação saudável e de educação ambiental. Esta vem sendo incentivada através de ações como política pública no decreto $\mathrm{n}^{\circ} 7.794$ de 20 de agosto de 2012, que institui a Política Nacional de Agroecologia e Produção Orgânica, possibilitando a elaboração do Plano Nacional de Agroecologia e Produção Orgânica - PLANAPO em 2013 (BRASIL, 2012; BRASIL, 2013).

Trazendo para nossa realidade e criando um sistema de bem-estar entre moradores e a escola, pode-se ampliar o conceito de promoção de saúde, com significativas repercussões no meio urbano, em políticas de promoção à saúde para favorecer uma responsabilização maior com sua própria saúde e com a saúde do planeta, e isso levaria a uma perspectiva de maior prevenção (AZEVEDO \& PELICIONI, 2012). Análises de custo-eficácia documentam que mesmo reduções modestas na ingestão de sódio pela população, por exemplo, teriam efeitos benéficos sobre a saúde das pessoas e determinariam grande redução nos gastos com o tratamento de doenças (SARNO, 2013).

Nas comunidades, a escola é um espaço onde muitas pessoas convivem, aprendem e trabalham, e no qual os estudantes passam a maior parte do tempo. Ao pensarmos no papel da escola é fundamental considerarmos a sua autonomia administrativa e pedagógica, para prover a expansão do atendimento e empregar os recursos financeiros recebidos, com a finalidade de oferecer um ensino igualitário a seus alunos (CARMIGNOLLI et al, 2019).

É sabido que na escola programas de apoio à educação e saúde podem ter maior repercussão e alcance para as pessoas envolvidas e todo o entorno. É dever social e obrigatório da escola socializar o conhecimento científico à população, de forma que essa se aproprie da cultura elaborada pelo conjunto social (CASSAB, 2016). A escola deve ser um local propício para práticas democráticas, um espaço em que todos os sujeitos envolvidos tenham oportunidade de expressar suas ideias, refletir e defendê-las (FREIRE, 1996; ASSMANN, 2012). Dessa forma, todos envolvidos no ambiente escolar, sejam os professores ou demais profissionais, tornam-se exemplos e referências para os alunos e suas famílias.

O discurso pedagógico, no contexto educacional, dentro do modelo escolar moderno, produz um saber sobre a criança, definindo-a e atribuindo-lhe uma identidade (FERRAZ \& PAGNI, 2019), moldando sua personalidade e uma atitude crítica em relação ao mundo. O ensino dos filhos está carregado de expectativas para a construção de uma infância baseada em princípios educativos que 
promovam o lúdico, a socialização e o compartilhamento de saberes socialmente construídos (PESSANHA, 2019).

Desde cedo se faz importante a frequência da criança na escola é obrigatória, conforme a legislação e políticas públicas que assegurem a educação infantil. Entretanto, muitas vezes não são levadas em consideração as demandas pessoais, peculiaridades e características, ponderando apenas a inserção social da criança e do jovem. O objetivo de tal costume é ajustar a infância segundo os saberes entremeados pelos adultos e que esses constroem sobre ela, saberes esses que lhes permitem conceituar, classificar, diagnosticar e prognosticar a infância (DANELON, 2015). Com isso, mantemos valores engessados que não condizem com os nossos ou deixam lacunas que são de suma importância, a exemplo da sustentabilidade ambiental, da economia verde, da agroecologia e do contato com espaços em que a natureza se faz presente, e é valorada.

Desenvolvendo atividades práticas nas escolas sobre os ciclos alimentares, por exemplo, os integramos aos ciclos de plantio, cultivo, colheita, compostagem, reciclagem, entre outras. O desejo infantil de que as instituições se ajustem as necessidades das etapas de vida dessas crianças, devem tornar o ambiente atrativo e motivador, características realmente importantes para que, de fato, ocorram aprendizagens significativas (ROSADO, 2011). Pode-se dizer que existem muitas maneiras de conhecer a natureza e aprender com sua sabedoria, por exemplo, a utilização de hortas comunitárias se configura como outra importante ferramenta, quando combinados com fundamentos básicos da alimentação, enriquecendo as práticas escolares. Esse desafio amplia a visão holística do sistema como um todo e proporciona a criação de práticas pedagógicas mais atrativas e dinâmicas.

A criança só pode conhecer ou construir seus conhecimentos através da ação individual que exerce sobre os objetos. Seguindo o pensamento de Piaget (2000), existe uma complexa relação entre os processos biológicos (maturação de mecanismos inatos) e as experiências físicas ou sociais que resultam na aprendizagem. Dessa maneira, se faz importante inseri-los no contexto, trazendo para a criança desde pequena a importância e responsabilidade a respeito da sua alimentação, para que essa preocupação se torne algo benéfico em sua vida.

A proposta de inserção da Agricultura Orgânica e da Agroecologia nas escolas contribui na interlocução entre o conhecimento técnico e o popular, expondo as alternativas para produção de alimentos saudáveis, assim como a importância quanto à procedência dos alimentos que consumimos, e a preferência por alimentos saudáveis dos vários grupos de cereais, verduras, legumes e frutas, tudo isso junto à comunidade diretamente envolvida no município.

O objetivo deste trabalho foi, portanto, descrever a experiência da utilização da Agroecologia e Agricultura Orgânica como ferramenta pedagógica de educação ambiental e alimentar, a crianças 
de 9 e 10 anos, $6^{\circ}$ ano, na Escola Estadual Professor José Luiz de Mesquita, no município de Lavras-MG.

\section{Percurso Metodológico}

O trabalho foi realizado com total de 39 alunos, de duas turmas do $6^{\circ}$ ano, da escola Estadual Professor José Luiz de Mesquita, do bairro COHAB no município de Lavras, MG, e que tinham em sua maioria 10 anos de idade, no ano de 2014. O projeto foi subdividido em 13 atividades de vivências dentro e fora da escola com a participação de estudantes universitários, professores, especialistas e membros do Núcleo de Estudos em Agricultura Orgânica (NEAGRO), da Universidade Federal de Lavras - UFLA.

O NEAGRO trabalha com extensão rural, desenvolve atividades na Horta da COHAB e outras atividades de educação ambiental em Lavras e região, e busca meios de maior aproximação e consolidação de laços entre a comunidade e a universidade, além de enriquecer e propiciar uma formação acadêmica mais holística, sistêmica e dinâmica aos alunos. Os integrantes do NEAGRO têm conhecimento sobre diversos assuntos relacionados à Agroecologia e Agricultura Orgânica, como adubação verde, controle biológico, plantas medicinais e como fazer hortas verticais, que permitiriam, de maneira didática, prática, fácil e lúdica o aprendizado pelas crianças.

A proposta foi desenvolvida de acordo com a Extensão Rural Inovadora (BRASIL, 2010) e metodologias participativas (LEFÈVRE, 2013; VERDEJO, 2006). A princípio foi feita uma roda de conversa com a coordenação pedagógica e professores, com intuito de apresentar a proposta e conhecer a escola. Posteriormente, foi realizada uma apresentação sobre agricultura a fim de estreitar a relação com as crianças, que era quase inexistente, e apresentar a proposta de trabalho tanto para as crianças, como para os profissionais que estariam envolvidos.

Após esse diálogo inicial e aceite em participar do projeto por parte da escola, foi feito o planejamento participativo das atividades a serem desenvolvidas no decorrer do período letivo. O trabalho ocorreu de forma sistemática e contínua, observando o desenvolvimento e a compreensão, através de atividades descritivas e orais, com a atuação dos atores envolvidos no que se refere à sua participação, e atitudes perante a importância e a necessidade de se preservar o meio ambiente. Seguindo essa mesma linha e adequando a realidade local, solicitamos à escola para que elaborássemos o cronograma junto com as crianças a fim de envolvê-las ainda mais no processo de construção. 
As atividades foram divididas em três etapas: 1) Levantamento de dados secundários, feito através de pesquisas orientadas em livros, jornais, revistas, informações oficiais dos governos em cunho municipal e estadual, sobretudo quanto à realidade do município e do entorno da escola; 2) Reuniões participativas de planejamento e avaliação com a escola (professores e alunos) a respeito da execução do projeto de educação ambiental e alimentar, e definição de direitos, deveres, responsabilidades e tarefas dos parceiros envolvidos no Projeto, além da observação e análise do espaço físico a ser utilizado; 3) Atividades teóricas e práticas de capacitação com as crianças em áreas temáticas específicas, relacionadas à Agroecologia e Agricultura Orgânica, e seus respectivos objetivos, apresentadas na Tabela 1.

\section{Tabela 1 - Cronograma de atividades desenvolvidas ao longo do Ciclo 1 e Ciclo 2 do projeto com as turmas da escola Estadual Professor José Luiz de Mesquita, do bairro COHAB, Lavras, MG, 2014}

\begin{tabular}{|c|c|}
\hline Atividades & Objetivos e local \\
\hline \multicolumn{2}{|r|}{$1^{\circ}$ ciclo } \\
\hline $\begin{array}{l}\text { 1. Apresentação: Quem } \\
\text { somos/Quem são eles? }\end{array}$ & $\begin{array}{l}\text { Primeiro contato com as crianças, onde ocorreram apresentações individuais sobre a } \\
\text { relação com a terra e a agricultura na escola. }\end{array}$ \\
\hline 2. História da Agricultura. & $\begin{array}{c}\text { Introdução do início da Agricultura com utilização de fotos, imagens antes da } \\
\text { evolução dos sistemas agrários na escola. }\end{array}$ \\
\hline 3. História da Agricultura. & $\begin{array}{c}\text { Revolução verde, modernidades na agricultura com fotos, imagens, linha do tempo na } \\
\text { escola. }\end{array}$ \\
\hline 4. História da Agricultura. & $\begin{array}{l}\text { Papel da mulher na agricultura e domesticação das plantas; trabalho em grupos na } \\
\text { escola. }\end{array}$ \\
\hline 5. Horta & $\begin{array}{l}\text { Com a utilização de PETs. Foram feitas mudas de salsinha, hortelã e manjericão na } \\
\text { escola. }\end{array}$ \\
\hline 6. Questic & Aplicamos o questionário: Que bom? Que pena? Que tal? Na escola. \\
\hline 7. Visita a horta-Cohab. & $\begin{array}{c}\text { Conhecer o sistema de horta comunitária em que estão inseridos, na própria horta } \\
\text { comunitária do bairro. }\end{array}$ \\
\hline \multicolumn{2}{|r|}{$2^{\circ}$ ciclo } \\
\hline $\begin{array}{l}\text { 8. Atividades em sala de } \\
\text { aula. }\end{array}$ & $\begin{array}{c}\text { Dinâmica e interação com as crianças - atividade em círculo com música interativa na } \\
\text { escola. }\end{array}$ \\
\hline $\begin{array}{l}\text { 9. Atividades em sala de } \\
\text { aula. }\end{array}$ & Atividades de recreação na escola. \\
\hline $\begin{array}{l}\text { 10. Tema: Controle } \\
\text { Biológico. }\end{array}$ & Demonstrações in vivo e das coleções do laboratório de entomologia na Universidade. \\
\hline $\begin{array}{l}\text { 11. Tema: Visita ao horto / } \\
\text { Plantas medicinais. }\end{array}$ & $\begin{array}{l}\text { Plantas espontâneas e de crescimento rápido, utilidade de algumas plantas medicinais } \\
\text { e outras com efeito anestésico na Universidade. }\end{array}$ \\
\hline 12. Contextualização. & $\begin{array}{l}\text { Espaço reservado aos docentes da escola junto com universitários expondo o que foi } \\
\text { importante com o trabalho na escola. }\end{array}$ \\
\hline $\begin{array}{l}\text { 13. Entrega do jornal da } \\
\text { escola. }\end{array}$ & $\begin{array}{l}\text { Entrega de material de apoio e finalização do jornal da escola, essas feitas com } \\
\text { depoimento das próprias crianças sobre o projeto na escola. }\end{array}$ \\
\hline
\end{tabular}

Fonte: Do autor.

O primeiro ciclo aconteceu no primeiro semestre de 2014, e o segundo ciclo durante o segundo semestre do mesmo ano letivo. Durante a execução do projeto, de forma participativa, foram sendo realizadas avaliações com os alunos e professores a respeito do andamento do projeto, 
através de questionário simples, aplicados ao final do Ciclo 1 e durante as atividades do Ciclo 2, com o intuito de registrar as expectativas dos alunos em relação ao desenvolvimento das atividades. Utilizamos as perguntas “Que bom?”, “Que pena?” e “Que tal?” para medirmos os pontos positivos e negativos, qualitativamente, bem como, as propostas vindas dos próprios alunos quanto ao que esperavam das dinâmicas realizadas no decorrer do projeto. Todo trabalho foi realizado sob a ótica da interdisciplinaridade e da relação horizontal entre adultos e crianças, deixando claro para elas a sua autonomia e liberdade de expressão.

Os primeiros encontros de cada ciclo, foram realizados dentro da escola com exposições teóricas através de cartilhas didáticas, ilustradas e dinâmicas, algumas das quais nós mesmos elaboramos com recursos mínimos, baseados em outros trabalhos já realizados na área da educação pelo NEAGRO. Facilitamos o entendimento e oferecemos uma dinâmica ao processo de aprendizagem, fazendo referência desde o início da agricultura, passando pela Revolução Verde, até os tempos mais modernos, sem se apegar a datas, apenas citando a sua ocorrência e também o papel fundamental da mulher na agricultura.

A atividade se deu por temas, divididos em encontros que aconteceram a cada quinze dias respeitando os períodos de férias da Universidade e da Escola ao longo de um ano. Temas como a introdução à agricultura, a importância de conhecer os alimentos que consumimos e como eles são produzidos, foram trabalhados com recortes de jornais e revistas para a construção de uma linha histórica com as crianças. Dessa forma, as crianças se localizavam no tempo de maneira didática, sendo instigadas a darem palpites quanto à época dos acontecimentos e o que elas imaginavam que poderia ter acontecido caso tivéssemos tomado um caminho diferente. Por exemplo, a importância da Revolução Verde e suas consequências, e o porquê de termos escolhido esse caminho que visa produção de alimentos em quantidade sem pensar em sustentabilidade.

As análises das respostas foram organizadas visando obter "por procedimentos sistemáticos e objetivos de descrição do conteúdo das mensagens, indicadores (quantitativos ou não) que permitam a inferência de conhecimentos relativos às condições de produção/recepção (variáveis inferidas) destas mensagens” (BARDIN, 2011, p. 47). Por condizer mais com o público alvo e a realidade do município, junto a uma abordagem qualitativa, como propõem Godoy (1995), Bogdan \& Biklen (2013), Rosado (2011) e Dutra (2017), onde a preocupação maior é com o processo avaliativo, que valoriza o ponto de vista do aluno e seus dados são de caráter descritivo. Nesse sentido, nós enquanto pesquisadores buscamos por meio de uma pré-análise compreender as características e estruturas que estão por trás das respostas descritivas e comportamentais das 
crianças envolvidas no trabalho, uma exploração dos questionários respondidos e por fim um tratamento desses resultados com a intenção de interpretá-los.

Programamos também visitas técnicas à Horta Comunitária do bairro e à Universidade com a intenção de implementar um sistema diferenciado de Extensão Inovadora, voltada à educação ambiental na escola da comunidade, partindo dos princípios da Agricultura Orgânica e Agroecologia como referencial central, servindo como elemento motivador para

a definição de uma estratégia territorial de extensão. Criamos assim, um vínculo de amizade e confiança entre os alunos e professores da UFLA envolvidos e a comunidade escolar da Escola Estadual Professor José Luiz de Mesquita.

\section{Análise e discussão dos resultados}

Estudos afirmam que poucos são os que têm acesso direto aos conhecimentos gerados na universidade pública e que a extensão universitária é imprescindível para a democratização do acesso a esses conhecimentos (MENDONÇA \& SILVA, 2002), assim como para o redimensionamento da função social da própria universidade, principalmente se for pública. Com a breve análise de conteúdo das informações do primeiro encontro com as crianças, foi possível identificar a dimensão 'Estar fora da Escola'. Essa resposta apareceu no primeiro questionário de avalição participativa feito com os alunos, e todas as crianças que receberam os questionários responderam de boa vontade. Foram poucas crianças quem não responderam, uma ou outra pergunta e, alguns alunos que haviam faltado no dia que disponibilizamos os questionários. Esse mesmo questionário foi aplicado em um segundo momento, no decorrer do segundo ciclo.

Observamos um enorme interesse em participarem das atividades de aprendizagem, principalmente fora do âmbito escolar. Os processos de ensino e aprendizagem são desenvolvidos ao longo da vida dos sujeitos, em diferentes espaços (ANDRADE, 2013) refletindo sobre a construção de relações mais democráticas, elegendo o diálogo como um eixo central na construção de "lugares exotópicos", que venham reafirmar o fortalecimento do processo de democratização escolar (PESSANHA, 2019). Mais da metade dos alunos levantou a experiência como oportunidade principalmente para aprendizagem, incluso o interesse em como é feito um plantio, sua colheita e o manejo de plantas que utilizamos na nossa alimentação diariamente.

A Agroecologia é a ciência que busca agroecossistemas sustentáveis, com equilíbrio entre plantas, solo e microrganismos, água, luz solar, fauna, e demais elementos (AQUINO \& ASSIS, 2007). O manejo agroecológico, que visa o uso adequado dos recursos para redução dos impactos 
sociais, econômicos e ambientais negativos vem a somar quando o objetivo é introduzir esse conhecimento. Após uma abordagem do conceito, foram mencionadas as bases e premissas que sustentam esse campo do saber, quanto ao empoderamento dos seus atores em conjunto com a sociedade a médio e longo prazo, estilos de agricultura que apresentam suporte ecológico e obtém produtos de qualidade superior, em relação aos convencionais, dando ênfase na importância do conhecimento da origem do alimento que colocamos dentro de casa e fazemos uso constante junto com a nossa família.

A disseminação de alternativas e tecnologias à Agroecologia corresponde a um amplo conjunto de arranjos produtivos socioeconômicos recentes ou tradicionais (SANTOS \& CHALUB-MARTINS, 2011). Projetos de implantação de hortas comunitárias, seguindo os princípios da Agroecologia, têm como finalidade promover atividades individuais e coletivas de práticas saudáveis de alimentação, socialização, solidariedade e conscientização ambiental, promovendo atividades que permitam aos sujeitos envolvidos, um avanço conforme seu ritmo, ou seja, oportunizando a superação das suas limitações e reconhecendo a importância do meio ambiente para os seres vivos em função de uma vida melhor. Com essa proposta podemos preencher lacunas e conectar pontos para a abertura de novos caminhos e possibilidades múltiplas de construção de interpretação e entendimentos, introduziremos a noção de educação menor proposta por Gallo (2012, p. 26):

Se uma educação maior é aquela do âmbito das políticas de ensino gestadas nos ministérios e secretarias, a dos grandes planos, dos macroplanejamentos, uma educação menor é aquela que se pratica nas salas de aulas, entre as quatro paredes, no âmbito do pequeno, como resistência, como produção de algo que se coloca para além e para aquém das grandes políticas. (GALLO, 2012, p. 26.)

Sendo assim, foi possível ter uma maior interlocução entre o conhecimento técnico, as alternativas para diversas situações que tangem a presente proposta e a comunidade diretamente envolvida, além de contribuir com a formação acadêmica e cidadã dos estudantes universitários envolvidos direta ou indiretamente no projeto.

Os professores, em suas atividades pedagógicas diárias, escolhem metodologias que julgam condizentes, elaboram tarefas e administram aulas mantendo a ordem (LIMA, 2016), porém, quando se extravasa para o âmbito externo à escola, proporcionando um novo ambiente de aprendizagem, podemos obter resultados fantásticos e perceptíveis. O presente trabalho foi desenvolvido sobre essa ótica, de forma a oferecer subsídio e vivências diferentes daquelas na qual as crianças estavam habituadas. Lima (2016) afirma que os resultados na educação são conquistados em longo prazo, nesse sentido, os professores dificilmente podem avaliar seu próprio progresso em relação ao alcance desses objetivos. Isso faz com que seja difícil quantificar o quanto 
um professor tem progredido na sua tarefa como educador. Por outro lado, é inquestionável as lembranças e importância do papel desses professores na vida de cada criança, servindo a essas de inspiração, modelo de adulto que constroem em cima do indivíduo “professor”, um amigo no qual ela pode confiar.

Basicamente, o método aplicado não deixa transparecer para as crianças que elas estão sendo avaliadas, e todo o processo é organizado de maneira bem simples, onde acontece uma pré-análise das respostas obtidas e dos demais materiais criados em conjunto, para depois ser feita sua sistematização. Essa fase é conhecida como a fase de 'leitura flutuante', onde nos deixamos levar por impressões e hipóteses acerca das respostas obtidas. Por isso, podemos conduzir os encontros esclarecendo, de maneira inicial e breve, as dificuldades das crianças acerca da Agricultura Orgânica e Agroecologia, o que pode contribuir para um melhor desenvolvimento dentro da sala de aula e na sociedade.

Fomos informados pela professora que para alguns dos alunos a universidade era paga, se tornando de difícil acesso para eles, que em sua maioria, são de família com renda baixa, o que pode gerar problemas de comportamento na criança, que não veem uma oportunidade palpável, tendo em vista, sua atual conjuntura econômica. Com isso, é gerado um sentimento de impotência, onde ainda que se dediquem e esforcem ao máximo, não terão as mesmas oportunidades que outras crianças mais afortunadas financeiramente. Sapienza (2005) afirma que famílias desestruturadas fazem parte de um grupo de risco para consequências negativas no desenvolvimento, incluindo frustração, falta de perspectivas, revolta, baixa estima e uma infinidade de outros desvios. A fim de exemplificação, Pansini \& Marin (2011) coloca que a escolarização das crianças menores de sete anos no Brasil foi marcada historicamente pela dicotomia entre creche - destinada às populações mais pobres - e pré-escola - frequentada pelas crianças de famílias de maior poder aquisitivo.

O direito das crianças à escola inclui não só o acesso, mas uma educação de qualidade que considere as necessidades infantis, entre as quais a de ser ouvida e respeitada (ROSADO, 2011). Das crianças em estudo, algumas delas fazem apenas uma alimentação durante todo o dia, aquela que é oferecida pela escola. Nesse sentido, como Lima (2016) ressalta, há uma exigência cada vez maior para que os professores se tornem profissionais da Pedagogia, capazes de lidar com os inúmeros desafios suscitados pela escolarização em todos os níveis de ensino. Saviani (2008) levanta a problemática da descontinuidade nas políticas públicas:

A outra característica estrutural da política educacional brasileira, que opera como um óbice ao adequado encaminhamento das questões da área é a descontinuidade. Esta se manifesta de várias maneiras, mas se tipifica mais visivelmente na pletora de reformas de que está povoada a história da educação brasileira. Essas reformas, 
vistas em retrospectiva de conjunto, descrevem um movimento que pode ser reconhecido pelas metáforas do ziguezague ou do pêndulo. A metáfora do ziguezague indica o sentido tortuoso, sinuoso das variações e alterações sucessivas observadas nas reformas; o movimento pendular mostra o vai-e-vem de dois temas que se alternam sequencialmente nas medidas reformadoras da estrutura educacional (SAVIANI, 2008, p. 11).

Devemos reforçar a importância de um novo modelo de ensino em que preconize a liberdade e a desoficialização, por parte do profissional docente, tentando imprimir um caráter prático na condução dos estudos, principalmente com crianças do ensino fundamental com idades entre 6 a 15 anos. As crianças se mostraram contentes por participar de atividades fora do espaço físico da escola, algo que julgamos importante para o seu crescimento. Um dos alunos fez uma observação quanto às visitas técnicas, afirmando: - Assim podemos expandir nosso campo de atuação social e ter novas experiências, se tornando pessoas melhores.

O aluno que tem a oportunidade de experimentar novos ambientes se mostra mais curioso e estimulado por sair da rotina que é, no ponto de vista deles, 'chata’ e monótona, mesmo com atividades que já são proporcionadas pela escola como, por exemplo, o laboratório de informática, que reforça o contato com a era digital e tecnológica, além de jogos interativos e educacionais. Também há na escola espaços de recreação, onde existe interação entre alunos de diferentes idades que trocam informações e participam de dinâmicas juntos, como ensaios com coreografias de dança entre as meninas e jogos de tabuleiro, futebol e cartas entre os meninos. O espaço físico condiciona nossos gestos diários, habitua nossa visão, estimula elementos simbólicos e estabelece pontos de referência. Se a escola não oferece espaço com áreas verdes e agradáveis aos sentidos, a criança se sentirá desestimulada a desenvolver relações saudáveis e equilibradas com o ambiente (FREITAS, 2014).

O enfoque do projeto foi a criança aplicar em seu cotidiano o que é aprendido com as vivências propostas e aprimorar sua visão de mundo em relação ao próximo, de tal forma que perceba a importância da ligação entre meio ambiente, economia e sociedade. Desse modo, amenizamos o cenário educacional brasileiro, em nosso contexto, conforme elucida Hugo Assmann (2012), é desolador, em especial nas escolas públicas.

Essa dinâmica favorece as relações interpessoais na comunidade, enfatizando atitudes e práticas pessoais/coletivas, estimulando a percepção e a atenção ao meio em que está inserido, trabalhando com conceitos de modo a apoiar as possibilidades de interação entre escolas, famílias e comunidade. Assim, buscamos também caminhar junto ao modelo agroecológico, incentivando o uso (pela produção em casa ou no bairro de forma comunitária) de alimentos saudáveis e nutritivos, 
que são feitos sem insumos químicos agrícolas por meio de jardins verticais, com uso de garrafas PET, pequenas hortas com hortaliças e condimentos.

Arrecadamos garrafas PET junto com a comunidade para confecção dos jardins verticais na escola, onde plantamos mudas de alecrim (Rosmarinus officialis) cedidas pelo Horto de Plantas Medicinais da universidade e sementes de salsinha (Petroselinum crispum) que compramos no comércio local, a fim de ensinar as crianças o plantio e manejo, influenciando-as em favor da saúde e bem-estar delas próprias e de suas famílias. Além de abordar os nomes populares e científico dessas espécies, a história e origem dessas plantas, seus principais usos, entre outras. Foi desenvolvido também, com acompanhamento das crianças uma composteira dentro da escola, para receber os resíduos de alimentos oriundos da cantina. Reforçando a importância de reaproveitamento desse resíduo de maneira simples, tomando alguns mínimos cuidados como o tipo de resíduo e a temperatura da pilha de resíduos. O composto resultante desse processo foi útil para a horta que foi reestabelecida com a turma. É de grande relevância proporcionar a socialização do conhecimento e alternativas para comunidade, percebendo-se como parte integrante da natureza e a importância do meio ambiente para os seres vivos de forma holística.

No campo educacional, existem diversos jeitos para se transmitir os saberes, todavia, a maioria dos educadores tende a se manter no caminho tradicional e engessado, se esquecendo de buscar novos processos que possam ajudar a transformar a educação em inovadora e satisfatória (IVANICSKA, 2016). As concepções de educação de qualidade influenciadas pelo mercado escolar acabaram por consolidar uma série de práticas (características estruturais e administrativas) adotadas pela instituição e que pode ser identificada como formas de construção de sua identidade. De forma oposta, se faz necessário valorizar as habilidades individuais, potencializando e estimulando as características individualmente e coletivamente, incentivando atividades e o trabalho com os conceitos de planejamento, além de conhecimentos multidisciplinares. Com isso, levamos essas crianças a despertar o senso crítico de como são produzidos os alimentos orgânicos e agroecológicos, basicamente hortaliças e a importância do consumo de alimentos mais saudáveis, sem o uso de qualquer agroquímico.

Dentro deste contexto e tendo em vista o desenvolvimento sustentável e diálogos entre universidade e sociedade, o Projeto vê na extensão inovadora, feita na base do diálogo humanista e participativo, o elo necessário entre as tecnologias e métodos aplicados pela Agroecologia e Agricultura Urbana aos diferentes atores locais (moradores das comunidades). No caso específico desta proposta, a ação foi voltada para os alunos do ensino fundamental, através desse projeto de educação ambiental que inseriu os alunos em práticas e noções agroecológicas paralelamente à 
instituição escolar. Essa que, como aponta Carmignolli et al (2019) ao desempenhar a função que lhe cabe, proporciona a todos os membros da sociedade o desenvolvimento de práticas culturais consideradas mais nobres, oferece também oportunidades diversificadas para essas frações ascenderem socialmente, através da utilização igualitária desses instrumentos, como é o caso dos projetos e iniciativas externas à escola.

Pela dinâmica proposta, alguns desafios importantes foram observados, sem que estivessem previstos na concepção inicial do trabalho. Observamos a preocupação das crianças quanto a se machucarem ou encontrarem animais peçonhentos, 'bichos', que poderiam lhes oferecer algum risco durante os passeios técnicos. Outra preocupação é quanto aos indivíduos (alguns próximos e até mesmo familiares dos próprios alunos) que fazem uso de drogas na região da horta, no próprio bairro em que o trabalho foi desenvolvido.

No início do trabalho expomos algumas dificuldades que poderíamos ter, por exemplo, em conseguir transporte, o que foi inclusive ressaltado por eles: - Seria uma pena se não conseguirmos transporte, ou se tivermos algum compromisso no dia, nos impedindo de participar da visita. Alguns sugeriram conhecer a Universidade e realizar tarefas práticas na horta, como o manejo e o cuidar das plantas, citando o plantio de algumas culturas como alface (Lactuca sativa sp.), beterraba (Beta vulgaris L.), cenoura (Daucus carota), e a possibilidade de levarem para casa o que eles mesmos plantaram, e ressaltamos o quanto isso seria bom para a sua formação. Essas propostas corroboram com o que Caporal (2006) propõem quando afirma que as metodologias utilizadas, em quaisquer intervenções, devem contribuir para a identificação do potencial endógeno das comunidades, ou seja, recursos localmente disponíveis que, se usados adequadamente, possam fortalecer processos de desenvolvimento mais sustentáveis. Por esse caminho metodológico foram estabelecidas as linhas de trabalho a serem desenvolvidas junto à escola e a comunidade, pautando ações individuais e coletivas no sentido da mudança.

Além dessas observações esperamos o fortalecimento e envolvimento crescente dos moradores da comunidade envolvida com a discussão do seu processo de desenvolvimento da Agroecologia e Agricultura Orgânica, e uma melhoria no processo de ensino, bem como a inclusão das comunidades carentes como ponto de destaque no ambiente universitário. Também propiciamos a aproximação da escola existente na comunidade com a realidade local, em uma busca de novas propostas pedagógicas que partam dessa realidade como elemento dinamizador do processo de ensino-aprendizagem e Extensão Universitária Inovadora. 
As atividades propostas na UFLA, visitas técnicas ao laboratório de Entomologia e ao Horto de Plantas Medicinais, se deram com uma média de 60 alunos (23 no primeiro dia e 37 no segundo). Foi observado pelas próprias professoras da escola que o considerado "pior aluno”, hiperativo, foi o que mais se destacou, dando respostas rápidas, no espaço interativo sobre controle biológico. Um profissional da educação necessita ter sensibilidade para lidar com o diferente, ser rígido quando for indispensável e tolerante quando houver necessidade (IVANICSKA, 2016).

Outra descoberta importante, observada com análise de conteúdo das informações, foi o interesse sobre a fisiologia de insetos. O que mais chamou atenção para as crianças foi quanto à fisiologia dos insetos e sua formação por: cabeça com um par de antenas, tórax com três pares de pernas e abdome. E os hábitos mais comuns, como acomunicação entre os insetos, por exemplo, e o uso de joaninhas (coleóptero da família Coccinellidae) para o controle de pulgões (Brevicoryne brassicae da família Aphidae), metamorfose da borboleta (lepidópteras) e o contato pela primeira vez com bicho-pau (Ctenomorphodes chronus). Como aponta Andrade (2013), a educação é um dos processos mais importantes para o interesse pela redução do uso de inseticidas, assunto esse que foi abordado com as crianças. É possível observar que os conceitos relacionados a este processo de aprendizagem, podem ser vivenciados desde a infância, com a compreensão e observação da diversidade de insetos e suas ações benéficas para o meio, como também para o ser humano (ANDRADE, 2013).

Os alunos pontuaram quanto aos insetos poderem ser benéficos ou maléficos a exemplo: Aedes aegypti que transmite dengue; abelhas (Apis mellífera da família Hymenoptera) são responsáveis pela polinização de flores nas plantas. Ao apresentar os insetos e suas características, foi perguntado por um deles quais danos os grilos (família Gryllidae) poderiam trazer, uma de suas colegas de sala respondeu que o grilo faz barulho, quando uma estudante que guiava o espaço disse que o barulho era o de menos as crianças não ficaram satisfeitas com a resposta, demonstrando não ser o de menos. Na educação oferecida no século XXI, se mostra indispensável conciliar aspectos que envolvam o intelectual, corporal e emocional, ressalta Ivanicska (2016). Podemos observar que as crianças assimilavam os insetos e suas características a experiências já vividas e ambientes do próprio dia-a-dia delas.

A turma do primeiro dia se mostrou calma e tranquila em relação a turma do segundo dia, se mantiveram em silêncio e interagindo pouco com as atividades e dinâmicas propostas. No entanto, na turma do segundo dia, que é considerada uma "turma com maior dificuldade quanto ao comportamento”, se destacaram cinco alunos, que participaram ativamente, levantando opiniões, considerações e dúvidas à cerca do assunto. Esta constatação nos faz refletir quanto aos métodos 
pedagógicos aplicados em sala de aula. Ferraz e Pagni (2019) faz referência a infinidade de regras do espaço escolar que objetivam a disciplinarização e a normalização dos corpos, a padronização excessiva das avaliações e práticas pedagógicas, a busca por métodos de penalizações "eficientes” para alunos “desviantes”, entre outros. Em alguns casos, turmas agitadas necessitam justamente de atividades práticas e extraclasses. Ou seja, assim como cada aluno tem sua própria dinâmica de aprendizagem, as turmas também apresentam as suas dinâmicas próprias, e é necessário construir metodologias diferenciadas para cada turma e suas respectivas especificidades, o que se apresenta como grande desafio ao professor.

É muito comum o espaço escolar ser visto como um espaço em que as crianças devem aprender a se comportar diante da sociedade e construir valores, muitas vezes não passados em casa. Sendo assim, as crianças são mandadas cedo à escola, não para que aprendam alguma coisa, mas para que se acostumem a ficar sentadas, obedecendo pontualmente o que lhes é mandado (KANT, 2006). Cabe ressaltar que a maior ou menor participação dos alunos nas atividades propostas, não significam necessariamente maior ou menor grau de aprendizagem dos alunos. Seria uma atitude equívoca e superficial? Entretanto, os resultados aqui apresentados, demonstram a importância de visitas a espaços fora do ambiente escolar.

No Horto de Plantas Medicinais foi levantado pelas crianças o uso de ervas como arruda (Ruta graveolens) para o combate ao piolho (Pediculus humanus), uso da hortelã (Mentha sp.), funcho (Foeniculum vulgare) para dores de barriga, plantas como agrião-bravo (Acmella uliginosa Sw. Cass.), utilizadas como anestésico e outras na indústria cosmética, como a babosa (Aloe vera). Foram feitas mudas de alecrim pelas próprias crianças, que posteriormente, após um mês na estufa, foram entregues para que pudessem levar para casa. Uma das alunas, no primeiro dia, perguntou se uma planta legalmente proibida seria uma planta medicinal. Acreditamos que essas curiosidades existem também entre outras crianças, mas que não são sanadas por serem um tabu, ainda que faça parte do contexto social. Essa conversa se deu de forma espontânea e caminhando entre os canteiros.

Aplicamos novamente o questionário, para compararmos com o mesmo aplicado antes, com as mesmas crianças. Com satisfação escreveram sobre o quanto foi bom e satisfatório a experiência, por terem aprendido muitas coisas, como plantar e ter trabalhado na horta da UFLA (em referência as mudinhas de alecrim que foram feitas nas dependências da Universidade). Algumas crianças não pontuaram nada de ruim, já outras pontuaram, por exemplo, o fato de alunos não respeitarem as plantas e estragarem a horta, como exemplo (em relação à falta de interesse pelos jovens em trabalhar com agricultura). Um pouco menos da metade sugeriu visitarmos a UFLA novamente, 
duas crianças disseram para que colocássemos vigias na horta, outras mais propuseram fazer o plantio de uva e morango.

No planejamento e execução do Projeto de educação ambiental e alimentar, buscamos contribuir com a formação acadêmica e cidadã também dos estudantes universitários envolvidos direta ou indiretamente no projeto, criando um vínculo de amizade e confiança entre professores da universidade, alunos e a comunidade. O intuito foi de promover o envolvimento das crianças da escola com a Agroecologia e Agricultura Orgânica no município, por meio de uma nova proposta metodológica que incentiva o uso (a produção em casa e/ou no bairro de forma comunitária) de alimentos saudáveis, nutritivos e que são produzidos sem insumos químicos agrícolas. Isso refletirá no melhor desenvolvimento físico e mental das crianças, influenciando a favor da saúde e no bemestar delas e de suas famílias. Desse modo estaríamos contribuindo para a melhoria do ensino escolar e valorização da educação como ferramenta transformadora da realidade.

\section{Considerações Finais}

Constatamos que oferecendo as ferramentas necessárias é possível construir conhecimento juntos, quanto à importância de se saber a procedência dos alimentos e mais ainda quanto aos benefícios que obtemos dos alimentos advindos da Agricultura Orgânica e Agroecológica, atentando também ao controle biológico, dando às próprias crianças maior autonomia.

As crianças possuem maneiras de aprender diferentes umas das outras, o que conferimos quanto ao comportamento daquelas crianças que não se destacavam dentro da escola, mas que participaram muito bem das atividades fora do âmbito escolar.

Observamos de maneira geral o quanto se tornou importante essa experiência na vida das crianças, desde as práticas dentro da própria escola junto a nós universitários, como também a oportunidade de conhecerem e se inteirarem do que é, de fato, a universidade e o que essa tem a nos oferecer, tema que deveria ser mais explorado, principalmente nas escolas de comunidades com grande vulnerabilidade socioeconômica.

A visita dos estudantes das escolas públicas aos espaços da universidade promove uma interação que ressalta e reforça o seu caráter público. Ambiente que deve ser integrado a comunidade que está inserida, para uso de suas estruturas, como laboratórios, espaços de pesquisa e ensino, criando e ampliado os laços e o diálogo entre a universidade e a sociedade.

A experiência foi de grande valia também, por parte dos alunos de graduação, professores e servidores da universidade envolvidos no projeto. Foi possível ver um outro universo, de certa 
forma mascarado, em virtude de não fazer parte direta do nosso dia a dia, nos fazendo repensar o modelo de universidade e sociedade em que queremos nos inserir.

\section{Referências}

ALMANZA, V. G. Rachel Carson: La escritura de lo ambiental. Cultura Científica e Tecnológica, n 33-34. p. 49-51 ano 6, 2009.

ANDRADE, R. C. Agricultura Urbana e Controle Biológico: Construindo estratégias participativas no município de Lavras, MG. 2013. p.133. Dissertação de mestrado em Controle Biológico de Pragas - Programa de Entomologia, UFLA, Lavras, 2013.

AQUINO, A. M.; ASSIS, R. L. Agricultura orgânica em áreas urbanas e periurbanas com base na agroecologia. Ambiente e Sociedade, Campinas, v.10, n.1, junho de 2007.

ASSMANN, H. Reencantar a educação: rumo a sociedade aprendente. $12^{\mathrm{a}} \mathrm{ed}$. Petrópolis, RJ: Vozes, 2012.

AZEVEDO, E.; PELICIONI, M. C. F. Agroecologia e promoção da saúde no Brasil. Revista Panam Salud Publica. vol.31, n.4, 290-295, 2012.

BARDIN, L. Análise de Conteúdo - L’Analyse de Contenu. Tradução de Luís Antero Reto e Augusto Pinheiro, Lisboa, edições 70, p.281, março de 2011.

BOGDAN, R. \& BIKLEN, S. Investigação qualitativa em educação: uma introdução à teoria e aos métodos. Ciência da Educação, Porto Editora, 2013.

BRASIL. Lei $\mathrm{n}^{\circ}$ 12.188, de 11 de janeiro de 2010. Institui a Política Nacional de Assistência Técnica e Extensão Rural para a Agricultura Familiar e Reforma Agrária - PNATER e o Programa Nacional de Assistência Técnica e Extensão Rural na Agricultura Familiar e na Reforma Agrária PRONATER, altera a Lei no 8.666, de 21 de junho de 1993, e dá outras providências. Diário Oficial da União, Brasília, 2010.

BRASIL. Decreto no 7.794, de 20 de agosto de 2012. Institui a Política Nacional de Agroecologia e Produção Orgânica. Presidência da República: Brasília, p. 4, 21 ago. 2012.

BRASIL. Ministério do Desenvolvimento Agrário. Brasil Agroecológico: Plano Nacional de Agroecologia e Produção Orgânica - PLANAPO. Brasília: MDA, 2013.

CAPORAL, F. R.; COSTABEBER, J. A. Agroecologia: alguns conceitos e princípios. Brasília: MDA/SAF/DATER-IICA. 2004.

CAPORAL, F. R.; COSTABEBER, J. A.; PAULUS, G. Agroecologia: Matriz disciplinar ou novo paradigma para o desenvolvimento rural sustentável, Brasília -DF, abril de 2006.

CARMIGNOLLI, A. O. L. et al. A influência do capital cultural no desempenho escolar. Educação em Foco, ano 22, n. 38 - set./dez. 2019.

CARSON R. Silent Spring. Houghton Mifflin. 27 de setembro de 1962.

CASSAB, M. Educação de Jovens e Adultos, Educação em Ciências e Currículo: Diálogos Potentes. Educação em foco, Juiz de Fora, v. 21 n. 1, p. 13-38, junho. 2016.

DANELON, J. R. B. Avaliação hídrica da bacia hidrográfica do Córrego do Glória, Uberlândia MG. 85 f. Dissertação (Mestrado em Ciências Humanas) - Universidade Federal de Uberlândia, Uberlândia, 2015. 
DUTRA, G. S. Desafios da prática docente no primeiro ano do Ensino Fundamental de nove anos. Perspectivas em Políticas Públicas. Belo Horizonte, Vol. X, nº 19, p. 53-87, junho 2017.

FERRAZ, K.; PAGNI, P. A. Educação escolar em perspectivas foucaultianas: um estudo do sujeito e do poder. Educação em Foco, ano 22, n. 38 - p. 91-112, set./dez, 2019.

FREIRE, P. Pedagogia da autonomia: saberes necessários à prática educativa. São Paulo: Paz e Terra, 1996.

FREITAS, H. B. A importância do Espaço Físico e Materiais Pedagógicos para as aulas de Educação Física na Escola Pública do município de Unaí - Trabalho de Conclusão de Curso (graduação) - Programa UAB/EaD da Universidade de Brasília, Buritis-MG, 2014.

GALLO, S. Metodologia do ensino de filosofia: uma didática para o ensino médio. São Paulo: Papirus, 2012.

GODOY, A. S. Pesquisa qualitativa: tipos fundamentais. Revista de Administração de Empresas, 35(4), 65-71, 1995.

IVANICSKA, R. F. A Sensibilidade na Formação Docente. Fazer Pedagógico e a Formação Docente. Congresso de Pesquisa e Extensão, UFMG, Barbacena, 2016.

KANT, I. Sobre a Pedagogia. 5aed. Piracicaba: Editora Unimep, 2006.

LEFÈVRE, V. et al. Farmers and agronomists design new biological agricultural practices for organic cropping systems in France. Agronomy for Sustainable Development, outubro. 2013.

LIMA, A. C. A et al. Os saberes dos docentes e as contribuições das pesquisas de Tardif para se repensar o trabalho docente, a pedagogia e o ensino. Caderno de Educação, n. 48, v.1, p. 09-23, 2016.

MENDONÇA, S. G. L.; SILVA, P.S. Extensão Universitária: Uma nova relação com a administração pública. Extensão Universitária: ação comunitária em universidades brasileiras. São Paulo, v. 3, p. 29-44, 2002.

PANSINI, F.; MARIN, A. P. O ingresso de crianças de 6 anos no ensino fundamental: uma pesquisa em Rondônia. Educação e Pesquisa, São Paulo, v.37, n.1, 220p. 87-103, jan./abr. 2011.

PESSANHA, F. N. O que esperamos para a educação de nossos filhos: diálogos com familiares dos meios populares no cotidiano da Educação Infantil. Educação em Foco, ano 22, n. 38, p. 6-21 set./dez. 2019.

PIAGET, J. Biologia e conhecimento: Ensaio sobre as relações entre as regulações orgânicas e os processos cognoscitivos (3. ed.). Psicologia da Inteligência. Petrópolis, RJ: Vozes, 2000. (Original publicado em 1967)

PIGNATI, W.A. et al. Distribuição espacial do uso de agrotóxicos no Brasil: uma ferramenta para a Vigilância em Saúde. Ciência saúde e coletiva, 22 (10) out 2017.

RAMOS, M. O. “As crianças estão se sentindo importantes”: avanços na alimentação escolar a partir da lei 11.947/2009 e da compra da agricultura familiar. Revista Trajetória Multicursos, Osório, Edição Especial, p. 4-19, agosto. 2011.

ROSADO, C. T. C. L; CAMPELO, M. E. C. H. Educação escolar: a vez e a voz das crianças. Ensaio: Avaliação e Políticas Públicas em Educação, Rio de Janeiro, v. 19, n. 71, p. 401-424, junho. 2011. 
SANTOS, F. P.; CHALUB-MARTINS, L. Agroecologia, consumo sustentável e aprendizado coletivo no Brasil. Educação e Pesquisa, vol.38, n.2, p. 469-484, outubro, 2011.

SAPIENZA, G.; PEDROMÔNIO, M. R. M. Risco, Proteção e Resiliência no Desenvolvimento da Criança e do Adolescente. Psicologia em Estudo, Maringá, 10, n. 2, p. 209-216, agosto. 2005.

SARNO, F. et al. Estimativa de consume de sódio pela população brasileira, Revista Saúde Pública, 47(3), 2013.

SAVIANI, D. Política Educacional brasileira: Limites e Perspectivas. Revista de Educação PUCCampinas, Campinas, n. 24, p. 7-16, junho. 2008.

VASCONCELOS, F. A. G. Josué de Castro e a Geografia da Fome no Brasil. Cad. Saúde Pública, Rio de Janeiro, 24(11), novembro. 2008.

VERDEJO, M.E. Diagnóstico Rural Participativo: um guia prático. Brasília, 2006.

ZIEGLER, Jean. Destruição em massa: geopolítica da fome. São Paulo: Cortez, 2013.

Recebido em: 07/04/2020

Aprovado em: 11/09/2020 